Erratum

\title{
Erratum to "Astaxanthin Attenuates Hypertensive Vascular Remodeling by Protecting Vascular Smooth Muscle Cells from Oxidative Stress-Induced Mitochondrial Dysfunction"
}

\author{
Yuqiong Chen $\mathbb{D}^{1},{ }^{1} \mathrm{Su} \mathrm{Li},{ }^{2}$ Yuxuan Guo ${ }^{1},{ }^{1}$ Hang $\mathrm{Yu},{ }^{1}$ Yandong Bao, ${ }^{1}$ Xin Xin, ${ }^{1}$ \\ Huimin Yang, ${ }^{1}$ Xinzhu Ni, ${ }^{1}$ Nan $\mathrm{Wu}^{3}$ and Dalin Jia ${ }^{1}{ }^{1}$ \\ ${ }^{1}$ Department of Cardiology, The First Affiliated Hospital of China Medical University, Shenyang, Liaoning, China \\ ${ }^{2}$ Department of Cardiology, Shanghai Institute of Cardiovascular Diseases, Zhongshan Hospital, Fudan University, Shanghai, China \\ ${ }^{3}$ The Central Laboratory, The First Affiliated Hospital of China Medical University, Shenyang, Liaoning, China \\ Correspondence should be addressed to Dalin Jia; jdl2001@126.com
}

Received 24 November 2021; Accepted 24 November 2021; Published 11 December 2021

Copyright (C) 2021 Yuqiong Chen et al. This is an open access article distributed under the Creative Commons Attribution License, which permits unrestricted use, distribution, and reproduction in any medium, provided the original work is properly cited.

In the article titled "Astaxanthin Attenuates Hypertensive Vascular Remodeling by Protecting Vascular Smooth Muscle Cells from Oxidative Stress-Induced Mitochondrial Dysfunction" [1], there was an error in Figure 5. A duplicate of the central panel in Figure 5(a) was erroneously uploaded as the final panel in Figure 5(a). The corrected figure is shown below and is listed as Figure 1: 


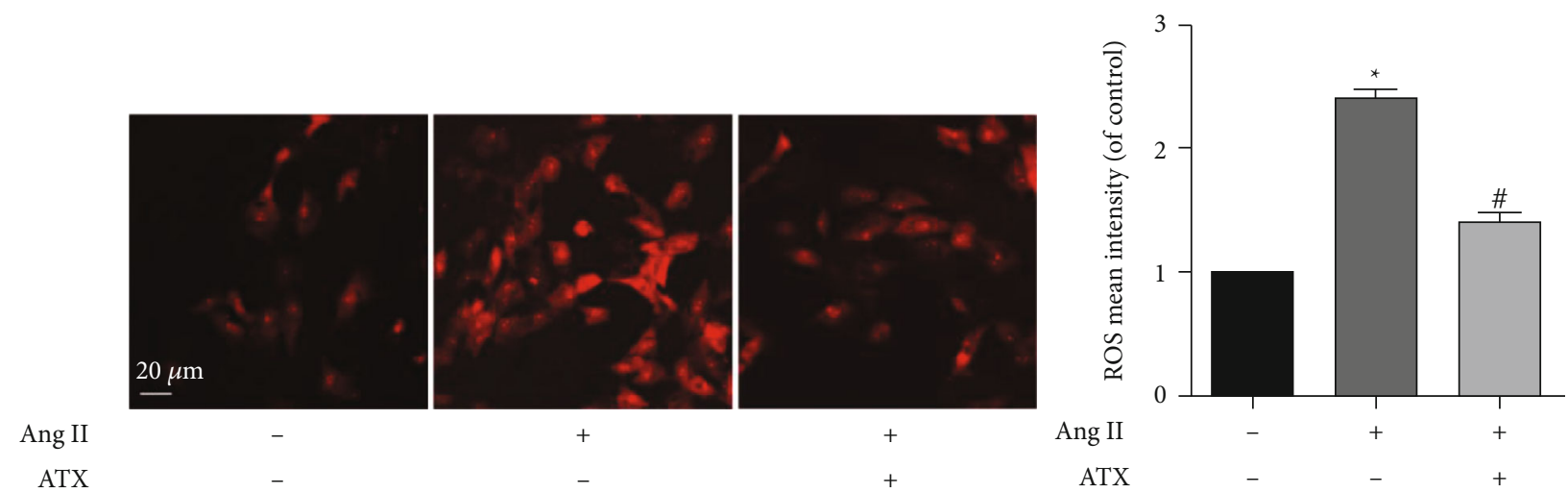

(a)
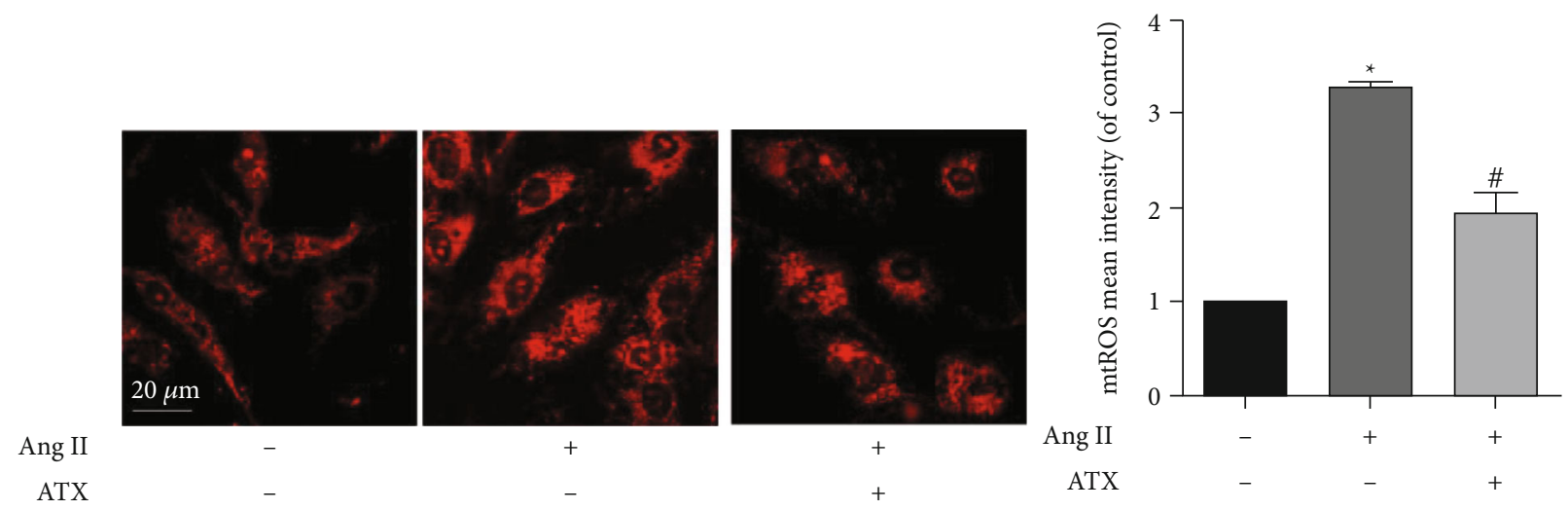

ATX

(b)

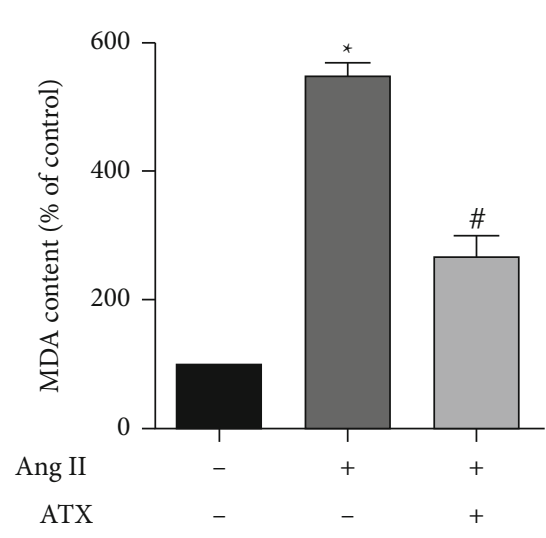

(c)

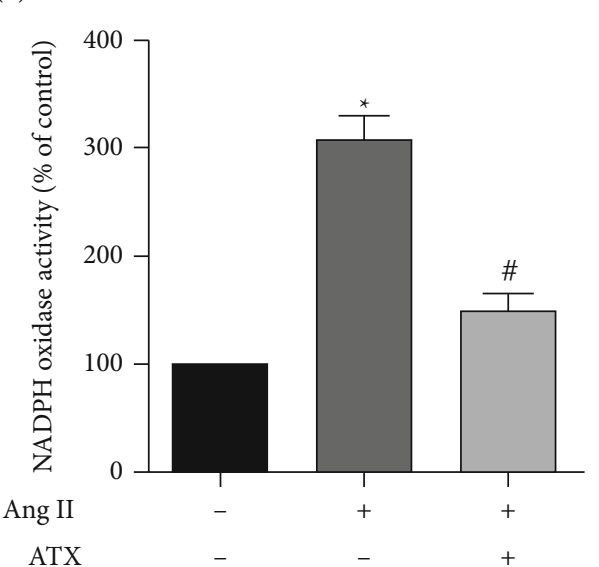

(d)

FIgure 1: Continued. 


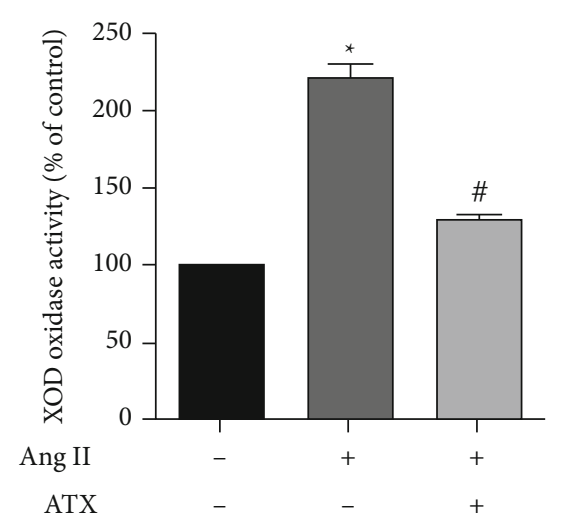

(e)

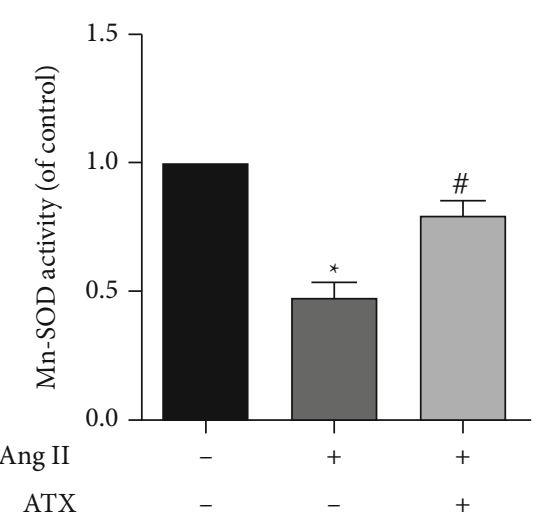

(f)

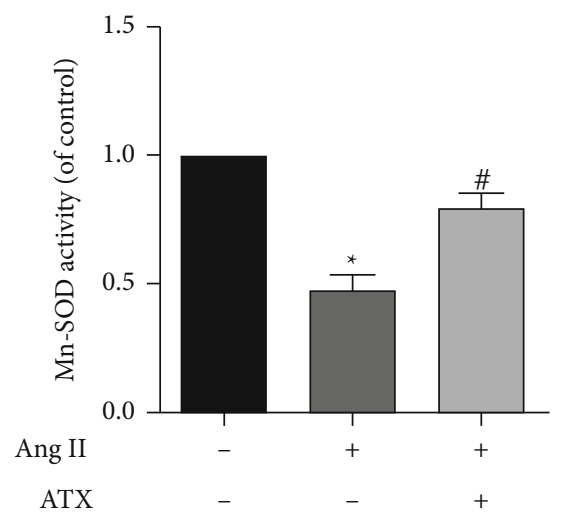

(g)

FIgURE 1: ATX decreases oxidative stress induced by Ang II in VSMCs. (a, b) Cellular ROS and mtROS of VSMCs were imaged by confocal microscopy, and the mean intensity of each group was quantified. Bar $=20 \mu \mathrm{m}$. The content of MDA (c) and the enzymatic activities of NADPH oxidase (d), xanthine oxidase (e), SOD (f), and Mn-SOD (g) of VSMCs in each group were analyzed. Values are represented as mean \pm SEM of 6 independent experiments. ${ }^{*} P<0.05$ vs. untreated controls; ${ }^{*} P<0.05$ vs. VSMCs injured by Ang II $(1 \mu \mathrm{M})$.

\section{References}

[1] Y. Chen, S. Li, Y. Guo et al., “Astaxanthin Attenuates Hypertensive Vascular Remodeling by Protecting Vascular Smooth Muscle Cells from Oxidative Stress-Induced Mitochondrial Dysfunction," Oxidative Medicine and Cellular Longevity, vol. 2020, Article ID 4629189, 19 pages, 2020. 